\title{
BMJ Open Prevalence of cardiovascular health and its relationship with job strain: a cross- sectional study in Taiwanese medical employees
}

\author{
Li-Ping Chou, ${ }^{1,2,3}$ Chiang-Chin Tsai, ${ }^{2}$ Chung-Yi Li, ${ }^{3,4}$ Susan $\mathrm{C} \mathrm{Hu}{ }^{3}$
}

To cite: Chou L-P, Tsai C-C, $\mathrm{Li} \mathrm{C}-\mathrm{Y}$, et al. Prevalence of cardiovascular health and its relationship with job strain: a cross-sectional study in Taiwanese medical employees. BMJ Open 2016;6:e010467. doi:10.1136/bmjopen-2015010467

- Prepublication history and additional material is available. To view please visit the journal (http://dx.doi.org/ 10.1136/bmjopen-2015010467).

L-PC and C-CT contributed equally.

Received 5 November 2015 Revised 3 March 2016 Accepted 10 March 2016

CrossMark

\footnotetext{
${ }^{1}$ Division of Cardiology, Department of Medicine, Sin-Lau Hospital, Tainan, Taiwan

${ }^{2}$ Department of Health Care Administration, Chang Jung Christian University, Tainan, Taiwan

${ }^{3}$ Department of Public Health, College of Medicine, National Cheng Kung University, Tainan, Taiwan

${ }^{4}$ Department of Public Health, China Medical University, Taichung, Taiwan
}

Correspondence to Dr Susan C Hu; shuhu@mail.ncku.edu.tw

\section{ABSTRACT}

Objectives: To explore the prevalence and associated factors of cardiovascular health as defined by the AHA among different job categories in health settings.

Methods: This is a cross-sectional and hospital-based survey. A total of 1329 medical professionals with a mean age of 38 years in a regional hospital in Taiwan were recruited. Information for seven combined indicators including blood pressure, fasting sugar, blood cholesterol, body mass index, time of physical activity, dietary pattern and smoking status was obtained from the employees' health profiles and questionnaires. Degree of job strain was evaluated by the Chinese version of the Job Content Questionnaire, which was derived from Karasek's demand-control model. Three types of cardiovascular health were identified as poor, intermediate and ideal.

Results: Prevalence of cardiovascular health in this study's population was ideal in $0.2 \%$ of the sample, intermediate in $20.6 \%$ and poor in $79.2 \%$. There was a significantly higher percentage of poor health in workers with high strain $(85.1 \%)$, and in the professions of nurse $(85.3 \%)$ and physician assistant $(83.1 \%)$. In the multivariate analysis, the only significant factor correlated with job strain was physical inactivity. After being adjusted, workers with high strain exhibit a higher prevalence of physical inactivity compared to those with low strain (OR $1.9,95 \% \mathrm{Cl}$ 1.38 to -2.81 ).

Conclusions: Physical inactivity is the only significant factor correlated with job strain and is associated with a work situation characterised by high strain and the professions of nurse and physician assistant. Strategies for workplace health promotion should focus on employee health literacy and motivation to exercise regularly.

\section{INTRODUCTION}

From epidemiological studies, cardiovascular diseases (CVD) are not only related to hypertension, dyslipidaemia and diabetes mellitus, but are also associated with unhealthy behaviour. ${ }^{1}$ A recently published population-based and prospective cohort study ${ }^{2}$ on Swedish

\section{Strengths and limitations of this study}

- This is the first report on the relationship of job strain with cardiovascular health as defined by the $A H A$, and it is also the first study to compare cardiovascular health status among different medical professions.

- Grouping poor cardiovascular health based simply on the presence of at least one poor cardiovascular indicator seems to lead to a major loss of information, which should be further validated.

- This study was based on questionnaires, so selective bias should be taken into consideration. The study may underestimate the prevalence of employees with high work loads and burnout. However, the high response rate will limit the magnitude of this underestimation.

- The participants were sampled from medical employees; therefore, the results should not be extended to other occupational workers.

men revealed that almost $4 / 5$ of myocardial infarctions in men are preventable by five low-risk behaviours. These low-risk behaviours include a healthy diet, no smoking, moderate alcohol consumption, physical activity and no obesity. However, only $1 \%$ of the men under consideration presented with all of the healthy behaviours included in this study. Another meta-analysis ${ }^{3}$ with data from seven cohort studies comprising 102128 men and women who were free of existing coronary artery disease at baseline (19852000), intended to measure the association of lifestyle factors and the incidence of coronary artery disease. There were four lifestyle risk factors: current smoking, physical inactivity, heavy drinking and obesity. Healthy lifestyle was defined as no risk factors, and unhealthy lifestyle was defined as 2-4 risk factors. After a mean of 7.3 years follow-up, the risk of coronary artery disease was higher in those who had an unhealthy lifestyle 
compared with those who had a healthy lifestyle (HR $2.55,95 \%$ CI 2.18 to 2.98 ; population attributable risk $26.4 \%)$

In 2010, the American Heart Association first offered 'simple life 7' as a goal for reducing cardiovascular risk factors and mortality. ${ }^{4}$ This approach combined seven indicators, which included four behavioural items (dietary pattern, physical activity, smoking status and body mass index (BMI)) and three risk factor items (blood pressure, blood cholesterol and fasting sugar level). Each indicator was divided into ideal, intermediate and poor statuses. Subsequently, one publication used the study's cohort from the National Health and Nutrition Examination Survey of 1999-2002 to validate the relationship between these 7 ideal health indicators and mortality from all causes and CVD. ${ }^{5}$ The results showed that the number of ideal cardiovascular factors was significantly and inversely related to the mortality from both, all causes and CVD. Compared with participants who possess none of the ideal metrics, those meeting $\geq 5$ indicators had a $78 \%$ (adjusted HR 0.22; $95 \%$ CI 0.10 to 0.50 ) reduction in the risk of all-cause mortality and an $88 \%$ (adjusted HR, 0.12; 95\% CI, 0.03 to 0.57 ) reduction in the risk of mortality from CVD.

Except for the above seven health metrics, psychosocial stress is considered to be an emerging risk factor for CVD. ${ }^{1}$ However, the plausible mechanisms of psychosocial stress-related causes of CVD remain unclear. One hypothesis links psychosocial stress with unhealthy behaviour and cardiovascular risk factors, which subsequently lead to developing CVD. ${ }^{6-8}$ Several studies have already reported the association of psychosocial stress with some of the above factors, such as obesity, physical inactivity, smoking, diabetes, dyslipidaemia and hypertension. ${ }^{9-11}$ However, no study has elucidated the relationship between psychosocial work characteristics and cardiovascular health status as defined by the AHA's 7 indicators.

Taiwan, as is the case in other eastern Asian countries, is notorious for overtime work requirements that are much more severe than those characteristic of Western countries. ${ }^{12}$ To improve this unfavourable work situation, Taiwan's government has regulated weekly work hours to be less than $40 \mathrm{~h}$ for employees and $88 \mathrm{~h}$ (including duty time) for resident physicians. Even with these changes, medical staff still face highly stressful work environments. The stressors include hospital accreditation, medical malpractice lawsuits, high work load and inadequate staffing. ${ }^{13}{ }^{14}$ Taiwan's nurses and physician assistants have a higher prevalence of severe burnout than their counterparts in other countries. ${ }^{15}$

In this study, we selected job strain, which was derived from the dominant tool of Karasek's demand-control model, to represent psychosocial stress. A great amount of evidence has shown job strain to be related to an increased risk of coronary artery disease and CVD mortality over a three decade period. ${ }^{16-18}$ In this study, we intend to examine the association of job strain and cardiovascular health among medical employees. There are several goals in this study. First, we intend to investigate the distribution of cardiovascular health factors using the AHA's definition in four groups of job strain and in five categories of medical employees. Second, we want to examine the relationship between job strain and cardiovascular health among medical professions. Finally, we plan to explore which factors are related to high levels of job strain. We expect these results may add to our knowledge about job strain and its association with CVD and in turn may facilitate improvements in the health of hospital employees.

\section{METHODS}

\section{Participants}

The participants' profiles were obtained from the database of a health promotion survey conducted at Sin-Lau Hospital (SLH-HPS) in 2012. The detailed descriptions can be seen in our previous reports. ${ }^{15}$ Briefly stated, a total of 1329 participants were recruited, including 101 physicians, 570 nurses, 68 physician assistants, 216 medical technicians and 374 administrators, which resulted in an $89 \%$ response rate. The questionnaire was administered voluntarily using an electronic system. All the collected data from the participants were anonymised and de-identified prior to analysis. This study was approved by the Ethics Review Board of Sin-Lau Hospital (SLH-919-104-08).

\section{Sociodemographics and work conditions}

Sociodemographic information and work conditions were evaluated through the use of a self-administered questionnaire. Sociodemographic information included gender, age, marital status, educational level and medical profession. Work conditions consisted of work duration, work type, work hours and sleep hours. Work duration refers to years in the present position. Work type was divided into fixed day work, fixed night work and shift work. Work hours were calculated as average work hours per week in the previous month, and were categorised as normal $(\leq 44 \mathrm{~h})$ and overtime $(>44 \mathrm{~h})$. Sleep hours were classified as $<6 \mathrm{~h}, 6-8 \mathrm{~h}$ and $>8 \mathrm{~h}$ per day $(24 \mathrm{~h})$.

\section{Measurement of cardiovascular health status}

We selected the seven cardiovascular health indicators offered by the American Heart Association as our study variables. These seven metrics include four lifestyle (smoking status, dietary pattern, physical activity and BMI) and three risk factors (fasting sugar, total cholesterol and blood pressure). The personal lifestyles information was acquired from the questionnaire. Dietary pattern was decided by the number of days of eating more than five portions of fruits and vegetables $(5$ per day) in 1 week. Physical activity was counted as total time engaged in moderate or strenuous exercise per week. Smoking status was classified as never smoked, 
ex-smoker and current smoker. BMI was measured as body weight in kilograms divided by the square of body height in metres $\left(\mathrm{kg} / \mathrm{m}^{2}\right)$. The measurements of fasting glucose and total cholesterol were taken using routine fasting blood sampling. Blood pressure was measured by skilled technicians and followed the suggestion of the American Heart Association. ${ }^{19}$ At least two measurements of blood pressure were taken at each measurement session, and the average value was used as the study variable. The above seven metrics were each categorised into thee levels: ideal, intermediate and poor. The detail definitions and prevalence are presented in table 1 . The definition of ideal cardiovascular health was participants who had all the ideal health indicators, and poor cardiovascular health included participants who had at least one poor cardiovascular indicator. Intermediate cardiovascular health included participants who belonged to neither the ideal nor poor cardiovascular health group.

\section{Measurement of job strain}

We used the Chinese version of the Job Content Questionnaire (C-JCQ) to measure job strain. C-JCQ is well validated in the Taiwanese population, ${ }^{20} 21$ and is derived from the Karasek Demand-Control model, which is a dominant tool in the research field of job stress. ${ }^{22}$ Job demands represent psychosocial work load, and job control means decision latitude in work. As postulated in Karasek's model, work characterised by high job demand and low job control was classified as high strain work, which produces the highest risk of stressrelated illness. On the other hand, work combined with low job demand and high job control was categorised as low strain work, which creates the lowest risk of stressrelated illness. Work combined with high job demand and high job control, and work that consisted of low job demand and low job control, were classified as active jobs and passive jobs, respectively, which have risk of stress-related illness that falls between that of high strain and low strain work. According to the C-JCQ, job demand was assessed by seven questions (fast work, hard work, excessive work, insufficient time, intensive concentration, hectic work and insufficient manpower), and job control was assessed by nine questions (learning new things, non-repetitive work, creative work, allowing one's own decisions, high level of skills, freedom to make decisions, various tasks, influential opinions and developing one's abilities). Each question was measured on a fourpoint Likert scale, ranging from 1 (strongly disagree) to 4 (strongly agree). In this study, the job demand scores and the control were calculated separately and divided into a dichotomy by median values to indicate high (equal to or above the median) and low (below the median) values.

\section{Statistical analysis}

All the variables were recorded as numbers and/or percentages. One-wave analysis of variance was used to test

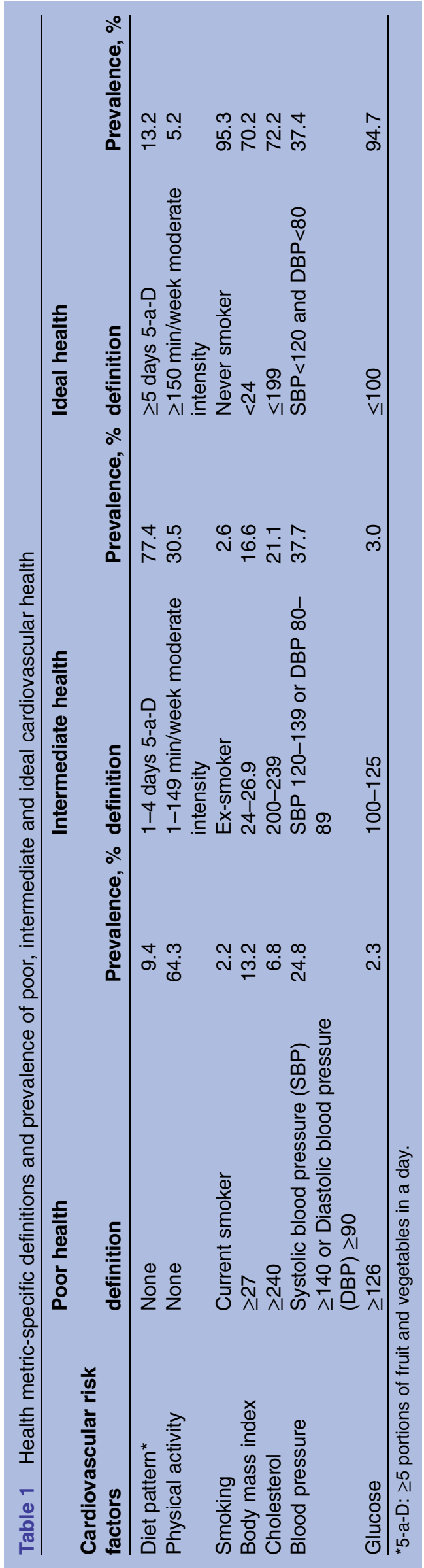


the difference between different groups regarding job strain and medical profession. Multiple logistic regression was used to explore the association of job strain with studying variables, and a multiple linear regression analysis was used to identify the relationship between job demand and job control with continuous variables. We chose SPSS V.17 software to perform all the statistical analysis; we set the level of significance at $\mathrm{p}<0.05$.

\section{RESULTS}

\section{Characteristics of participants}

A total of 1329 medical employees 21-64 years of age (average 38 years) were recruited. The sociodemographic factors and job-related psychosocial factors between four groups of job strain are summarised in table 2. Females and younger people (age <30 years) had a significantly greater prevalence of high strain. Among the different medical professions under consideration, physician assistants and nurses had a much higher percentage of work with high strain as compared with medical technicians, administrative staff and physicians $(27.9 \%, 27.2 \%, 14.4 \%, 14.7 \%, 2 \%$, $\mathrm{p}<0.0001)$. Jobs with high strain are more common in fixed night work and shift work than in fixed day work. This table also shows that longer work periods are associated with the high strain group. The distribution of jobs with high strain showed no differences in marital status, education level, work duration, or hours of sleep.

\section{Definitions and prevalence of a cardiovascular health profile}

Table 1 shows the definitions of seven cardiovascular health profiles. Most of them are similar to the AHA definition, with the exception of diet pattern and BMI. We chose to use more simple criteria (a healthy diet consisting of five fruits and vegetables per day) that was more

\begin{tabular}{|c|c|c|c|c|c|}
\hline Variable & Low strain & Passive & Active & High strain & p Value \\
\hline Gender (n, \%) & & & & & $\leq 0.001$ \\
\hline Male & $115(50.4)$ & $53(23.2)$ & $38(16.7)$ & $22(9.6)$ & \\
\hline Female & 325 (29.5) & 347 (31.5) & 189 (17.2) & $240(21.8)$ & \\
\hline Age, in years $(n, \%)$ & & & & & $\leq 0.001$ \\
\hline$\leq 30$ & $50(23.9)$ & $55(26.3)$ & $45(21.5)$ & 59 (28.2) & \\
\hline $31 \sim 40$ & $190(31.6)$ & $175(29.1)$ & $102(16.9)$ & 135 (22.4) & \\
\hline $41 \sim 50$ & $138(36.5)$ & $124(32.8)$ & 64 (16.9) & $52(13.8)$ & \\
\hline$>50$ & $62(44.6)$ & $45(32.4)$ & $16(11.5)$ & $16(11.5)$ & \\
\hline Marriage (n, \%) & & & & & 0.243 \\
\hline Single/others & $156(31.3)$ & $150(30.1)$ & $81(16.2)$ & $112(22.4)$ & \\
\hline Married & $284(34.2)$ & $250(30.1)$ & $146(17.6)$ & $150(18.1)$ & \\
\hline Education (n, \%) & & & & & 0.085 \\
\hline High school & $52(38.8)$ & $33(24.6)$ & $25(18.7)$ & $24(17.9)$ & \\
\hline College & $137(36.1)$ & $124(32.6)$ & $52(13.7)$ & $67(17.6)$ & \\
\hline University & $251(30.8)$ & $243(29.8)$ & $150(18.4)$ & $171(21.0)$ & \\
\hline Profession (n, \%) & & & & & $\leq 0.001$ \\
\hline Physician & $62(61.4)$ & $13(12.9)$ & $24(23.8)$ & $2(2.0)$ & \\
\hline Physician assistant & 19 (27.9) & $21(30.9)$ & $9(13.2)$ & 19 (27.9) & \\
\hline Nurses & $142(24.9)$ & $143(25.1)$ & $130(22.8)$ & 155 (27.2) & \\
\hline Medical technician & $95(44.0)$ & 64 (29.6) & $26(12.0)$ & $31(14.4)$ & \\
\hline Administrative Staff & $122(32.6)$ & $159(42.5)$ & 38 (10.2) & 55 (14.7) & \\
\hline Work, in years $(n, \%)$ & & & & & 0.748 \\
\hline$<5$ & $129(32.6)$ & $115(29.0)$ & $70(17.7)$ & $82(20.7)$ & \\
\hline $5 \sim 10$ & 92 (33.2) & 76 (27.4) & 48 (17.3) & $61(22.0)$ & \\
\hline$>10$ & $219(33.4)$ & 209 (31.9) & 109 (16.6) & 119 (18.1) & \\
\hline Work shift (n, \%) & & & & & $\leq 0.000$ \\
\hline Day shift & $267(41.8)$ & $191(29.9)$ & $97(15.2)$ & $83(13.0)$ & \\
\hline Night shift & $9(19.6)$ & $14(30.4)$ & $11(23.9)$ & $12(26.1)$ & \\
\hline In shift & $164(25.4)$ & $195(30.2)$ & 119 (18.4) & $167(25.9)$ & \\
\hline Work time (n, \%) & & & & & $\leq 0.000$ \\
\hline Normal & $357(34.8)$ & $347(33.8)$ & $130(12.7)$ & $193(18.8)$ & \\
\hline Overtime & $83(27.5)$ & $53(17.5)$ & 97 (32.1) & $69(22.8)$ & \\
\hline Sleeping hours ( $n, \%)$ & & & & & 0.877 \\
\hline$<6$ & $195(34.5)$ & $161(28.4)$ & $102(18.0)$ & $108(19.1)$ & \\
\hline $6 \sim 8$ & $230(32.2)$ & $223(31.2)$ & 116 (16.2) & $145(20.3)$ & \\
\hline$>8$ & $15(30.6)$ & $16(32.7)$ & 9 (18.4) & 9 (18.4) & \\
\hline
\end{tabular}




\begin{tabular}{|c|c|c|c|c|c|}
\hline Cardiovascular health factors & Low strain $(\mathrm{N}=440)$ & Passive $(\mathrm{N}=400)$ & Active $(\mathrm{N}=227)$ & High strain $(\mathrm{N}=262)$ & p Value \\
\hline Diet pattern (\%) & & & & & 0.718 \\
\hline Poor & 8.6 & 10.2 & 7.5 & 11.1 & \\
\hline Intermediate & 77.3 & 77.8 & 77.5 & 76.7 & \\
\hline Ideal & 14.1 & 12.0 & 15.0 & 12.2 & \\
\hline Physical activity (\%) & & & & & $\leq 0.001$ \\
\hline Poor & 55.9 & 64.0 & 67.4 & 76.3 & \\
\hline Intermediate & 37.0 & 32.5 & 26.9 & 19.5 & \\
\hline Ideal & 7.0 & 3.5 & 5.7 & 4.2 & \\
\hline Smoking status (\%) & & & & & 0.572 \\
\hline Poor & 2.3 & 1.8 & 3.1 & 1.9 & \\
\hline Intermediate & 3.6 & 2.3 & 2.2 & 1.5 & \\
\hline Ideal & 94.1 & 96.0 & 94.7 & 96.6 & \\
\hline Body mass index (\%) & & & & & 0.292 \\
\hline Poor & 11.8 & 11.8 & 15.4 & 16.0 & \\
\hline Intermediate & 19.1 & 15.8 & 16.3 & 13.7 & \\
\hline Ideal & 69.1 & 72.5 & 68.3 & 70.2 & \\
\hline Cholesterol (\%) & & & & & 0.311 \\
\hline Poor & 6.8 & 7.5 & 7.0 & 5.3 & \\
\hline Intermediate & 23.2 & 20.0 & 23.8 & 16.8 & \\
\hline Ideal & 70.0 & 72.5 & 69.2 & 77.9 & \\
\hline Blood pressure (\%) & & & & & 0.031 \\
\hline Poor & 24.4 & 26.7 & 30.8 & 17.2 & \\
\hline Intermediate & 40.8 & 34.5 & 36.2 & 38.9 & \\
\hline Ideal & 34.8 & 38.8 & 33.0 & 43.8 & \\
\hline Glucose (\%) & & & & & 0.045 \\
\hline Poor & 3.2 & 2.8 & 1.3 & 1.1 & \\
\hline Intermediate & 4.8 & 2.5 & 2.6 & 1.1 & \\
\hline Ideal & 92.0 & 94.8 & 96.0 & 97.7 & \\
\hline
\end{tabular}

suitable to the body size of a Taiwanese individual (BMI $\geq 27$ instead of BMI $\geq 30$ as a poor category). ${ }^{23}$ The prevalence of the ideal healthy diet and level of physical activity were found to be very low $(13.2 \%$ and $5.2 \%$, respectively) in this study population. On the other hand, the prevalence of never having smoked and ideal BMI were relatively high $(95.3 \%$ and $70.2 \%$, respectively).

\section{Distribution of cardiovascular health factors}

Table 3 shows the distribution of the seven cardiovascular health metrics among the four groups of job strain. It can be seen that there are no significant differences regarding healthy diet, smoking status, BMI, total cholesterol and fasting glucose. All the participants had a low percentage of physical activity of more than $150 \mathrm{~min} /$ week $(3.5-7 \%)$. The high strain group had the highest percentage of no regular physical activity (76.3\%), which was significantly different from the other groups $(p<0.001)$. On the contrary, the high strain group had a significantly lower percentage of hypertension and diabetes than the other groups $(\mathrm{p}=0.031$ and $\mathrm{p}=0.045$, respectively).

Online supplementary table S1 shows the distribution of the seven cardiovascular health metrics among the five groups of medical professions. Physicians had the highest percentage of current smoking, obesity and hypercholesteraemia, but they also had the highest prevalence of ideal physical activity compared to the other medical professions. These cardiovascular factors all exhibited significant differences among the medical professions. It is worthy of notice that a lack of physical activity is a very common phenomenon among medical professionals. The worst affected group is nurses, among whom only $1.9 \%$ exercised more than $150 \mathrm{~min} /$ week and $78.4 \%$ had no physical activity. There were no statistical differences regarding healthy diet, blood pressure and fasting glucose.

Table 4 demonstrates the distribution of health factors between the four job characteristics groups. The average numbers of health factors was 3.8, which showed insignificant differences among the four job strain groups.

\section{Cardiovascular health status in the job strain and medical professional groups}

Figure 1 shows the cardiovascular health status among the four groups of job strain. The results showed that the prevalence of poor cardiovascular health status from high to low was high strain, active strain, passive strain and low strain $(85.1 \%, 83.7 \%, 79.5 \%$ and $73.2 \%$, respectively) $(\mathrm{p}=0.002)$. Figure 2 shows the cardiovascular health status among the five medical professions. 
Table 4 Number of cardiovascular health factors by job strain

\begin{tabular}{|c|c|c|c|c|c|c|}
\hline \multirow[b]{2}{*}{$\begin{array}{l}\text { Number of health } \\
\text { factors }\end{array}$} & \multirow[b]{2}{*}{$\begin{array}{l}\text { Total, \% } \\
(\mathrm{N}=1329)\end{array}$} & \multicolumn{5}{|l|}{ Job strain } \\
\hline & & $\begin{array}{l}\text { Low strain, \% } \\
(\mathrm{N}=440)\end{array}$ & $\begin{array}{l}\text { Positive, \% } \\
(\mathrm{N}=400)\end{array}$ & $\begin{array}{l}\text { Active, \% } \\
(\mathrm{N}=227)\end{array}$ & $\begin{array}{l}\text { High strain, \% } \\
(\mathrm{N}=262)\end{array}$ & p Value \\
\hline 0 & 0.1 & 0.0 & 0.2 & 0.0 & 0.0 & 0.091 \\
\hline 1 & 1.2 & 1.4 & 1.5 & 1.3 & 0.4 & \\
\hline 2 & 8.0 & 11.1 & 5.0 & 10.1 & 5.3 & \\
\hline 3 & 25.4 & 24.5 & 27.0 & 25.1 & 24.4 & \\
\hline 4 & 42.1 & 40.0 & 43.5 & 41.9 & 43.5 & \\
\hline 5 & 2.9 & 20.9 & 20.5 & 18.5 & 23.7 & \\
\hline 6 & 2.3 & 1.8 & 2.2 & 2.6 & 2.7 & \\
\hline 7 & 0.2 & 0.2 & 0.0 & 0.4 & 0.0 & \\
\hline Mean $(n)$ & 3.8 & 3.7 & 3.8 & 3.8 & 3.9 & \\
\hline
\end{tabular}

The results demonstrated that nurses had the highest percentage of poor cardiovascular health $(85.3 \%)$ among the five medical professions, and physician assistants $(82.4 \%)$ were second to nurses. Similarly, there was a statistical significance among these five medical professions $(\mathrm{p}=0.0001)$. The total population exhibiting ideal cardiovascular health was $0.2 \%$, intermediate was $20.6 \%$ and poor cardiovascular health was $79.2 \%$.

\section{Associations between cardiovascular health factors and job strain}

The relationship between job demands, job control and job strain to the seven cardiovascular health factors is demonstrated in table 5. Through a multivariate analysis, the only significant factor that correlated with job demand, job control and job strain was physical inactivity (regression coefficients $0.412,0.258$ and 0.499 , respectively). This indicates that high job demands, low job control and high strain jobs are associated with a lack of physical activity. After being adjusted by age and gender, the prevalence of physical inactivity in a comparison of high strain, active and passive to low strain resulted in an OR of 1.9 (95\% CI 1.38 to -2.81 ), 1.4 (95\% CI 1.00 to -2.03 ) and 1.2 (95\% CI 0.93 to -1.67) (see table 6).

\section{DISCUSSION}

This is the first study to explore the relationship between job strain and cardiovascular health among

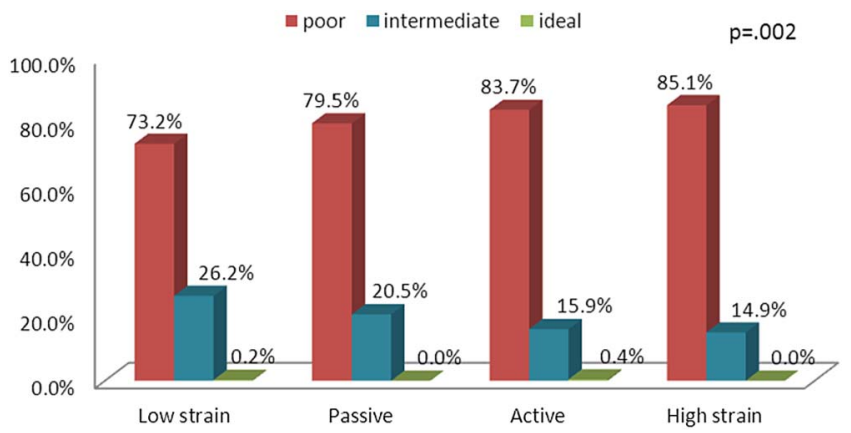

Figure 1 Prevalence of cardiovascular health status among the four groups of job strain. medical employees. The main findings show that (1) high job strain was associated with a greater prevalence of poor cardiovascular health; (2) nurses and physician assistants had the highest percentage of poor cardiovascular health in a hospital setting; (3) physical inactivity is the only factor related to work characterised by high job demand, low job control and high strain. Employees who have high strain work had $90 \%$ greater physical inactivity compared to those who worked in low strain jobs; and (4) the prevalence of an ideal healthy diet and physical inactivity was rare $(13.2 \%$ and $5.6 \%$, respectively) among the studied populations.

Previous studies have established the association of seven cardiovascular health indicators with the incidence and mortality of CVD. ${ }^{5}$ Folsom et $a l^{24}$ reported on the prevalence of ideal cardiovascular health as defined by the American Heart Association from four communities in America, with a total sampling of 15792 middle-aged participants from 1987 to 1989 as well as the incidence rate of CVD in a 20 -year period. They found only $0.1 \%$ of participants had ideal cardiovascular health; $17.4 \%$ had intermediate cardiovascular health and $82.5 \%$ had poor cardiovascular health. CVD incidence rates showed a good correlation with the three categories of health and with the number of ideal health metrics. Coronary artery disease incidence rates were much lower in those with the six ideal health metrics (3.9/1000 person-years) compared with those with zero ideal health metrics

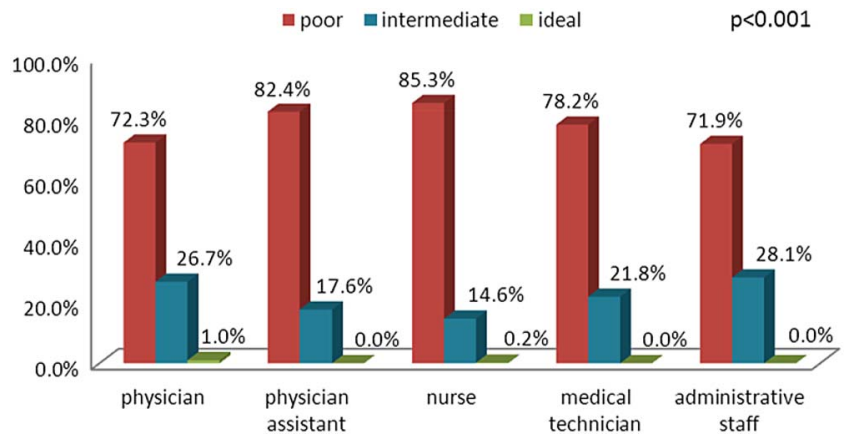

Figure 2 Prevalence of cardiovascular health status among five medical professions. 
Table 5 Regression coefficients (SEs) indicating the associations of job demand, job control and job strain, respectively, with cardiovascular risk factors

\begin{tabular}{|c|c|c|c|}
\hline Cardiovascular risk factors & $\begin{array}{l}\text { Job demand (high vs } \\
\text { low) }\end{array}$ & $\begin{array}{l}\text { Job control (low vs } \\
\text { high) }\end{array}$ & $\begin{array}{l}\text { Job strain (high strain vs } \\
\text { others) }\end{array}$ \\
\hline Unhealthy diet† & $0.012(0.199)$ & $0.300(0.192)$ & $0.277(0.229)$ \\
\hline Physical inactivity $\dagger$ & $0.401(0.129)^{*}$ & $0.262(0.121)^{*}$ & $0.506(0.165)^{*}$ \\
\hline Smoking & $0.728(0.421)$ & $0.312(0.409)$ & $0.608(0.555)$ \\
\hline Body mass index $\left(\mathrm{kg} / \mathrm{m}^{2}\right) \ddagger$ & $0.007(0.004)$ & $-0.001(0.004)$ & $0.000(0.003)$ \\
\hline $\begin{array}{l}\text { Systolic blood pressure } \\
(\mathrm{mm} \mathrm{Hg}) \ddagger\end{array}$ & $0.000(0.001)$ & $0.000(0.001)$ & $-0.001(0.001)$ \\
\hline $\begin{array}{l}\text { Diastolic blood pressure } \\
(\mathrm{mm} \mathrm{Hg}) \ddagger\end{array}$ & $-0.002(0.002)$ & $-0.001(0.002)$ & $-0.002(0.002)$ \\
\hline Glucose $(\mathrm{mg} / \mathrm{dL}) \ddagger$ & $0.000(0.000)$ & $-0.001(0.001)$ & $0.000(0.000)$ \\
\hline Cholesterol (mg/dL) $\ddagger$ & $0.000(0.000)$ & $0.000(0.000)$ & $0.000(0.000)$ \\
\hline
\end{tabular}

(37.1/1000 person-years). The prevalence of cardiovascular health status from our study was ideal $0.2 \%$, intermediate $20.6 \%$ and poor $79.2 \%$, which was very similar to the pattern reported by Folsom. Furthermore, we reported that those with high strain jobs exhibited the highest prevalence of poor cardiovascular health. This finding may suggest that workers with high strain jobs have more potential than workers in other situations, to suffer from CVD in later life. Another important finding in this report was that nurses and physician assistants also exhibited the highest percentage of poor cardiovascular health among the medical professions under consideration. The possible reason for this is that more nurses and physician assistants belong to the high strain group, so there may be a link to more adverse cardiovascular health.

After being adjusted for important demographic factors, physical inactivity was the only factor positively related to high job demands, low job control and high job strain. Also, after being adjusted by age and gender, employees with high strain and active strain are 90\% and $40 \%$ more likely to be physically inactive as compared to those with low strain (OR 1.9; $95 \%$ CI 1.38 to -2.82 and OR 1.4; $95 \%$ CI 1.00 to -2.03 , respectively). This finding is compatible with the results of a large-scale study from 14 prospective cohorts and eight European countries. ${ }^{25}$ However, $64.3 \%$ of our study population had no physical activity, which was much higher than the European (7\% to 38\%) and American $\left(24 \%\right.$ in 2005) ${ }^{26}$ samples. Ranking behind high blood pressure, smoking and high blood glucose, physical inactivity was the fourth most important risk factor for non-communicable chronic diseases, as reported by the WHO. ${ }^{27}$ Moreover, physical inactivity contributes to population-attributable risk that is only lower than the risk factor associated with smoking. Therefore, a sedentary life has not only become a world-wide phenomenon, but has also become a major public health burden. As O'Keefe argued, 'sitting is the new smoking, ${ }^{28}$

Physical inactivity has been reported to increase the relative risk of coronary artery disease, stroke, hypertension and osteoporosis by 45\%,60\%, 30\% and 59\%, respectively. ${ }^{29}$ On the other hand, regular physical activity will provide several substantial benefits to overall health. A large-scale prospective study observed 55137 participants with a mean age of 44 years and follow-up of 15 years. ${ }^{30}$ They concluded that running, even running $5-10 \mathrm{~min} /$ day at slow speeds, $<6 \mathrm{miles} / \mathrm{h}$, was associated with markedly reduced $(30 \%$ and $45 \%)$ risk of death from all causes and CVD, respectively. Moreover, runners get a 3-year life-expectancy benefit. Exercise also has benefits related to several CVD risk factors. Aerobic physical activity reduces low-density lipoprotein by an average of $3-6 \mathrm{mg} /$ day, reduces systolic blood pressure by an average of $2-5 \mathrm{~mm} \mathrm{Hg}$ and reduces diastolic blood pressure by $1-4 \mathrm{~mm} \mathrm{Hg}$, lowers blood sugar and increases insulin sensitivity, is dose-responsive

Table 6 OR of physical inactivity in association with types of job strain

\begin{tabular}{lllcc}
\hline Job strain & Number of Participants & Physical inactivity (\%) & Crude OR (95\% CI) & Adjusted† OR (95\% Cl) \\
\hline Low strain & 440 & 55.9 & 1 & 1 \\
Passive strain & 400 & 64.0 & $1.4(1.06 \text { to } 1.85)^{\star}$ & $1.2(0.93$ to 1.67$)$ \\
Active strain & 227 & 67.4 & $1.6(1.17 \text { to } 2.28)^{\star}$ & $1.4(1.00 \text { to } 2.03)^{\star}$ \\
High strain & 262 & 76.3 & $2.5(1.81 \text { to } 3.58)^{*}$ & $1.9(1.38 \text { to } 2.81)^{*}$ \\
\hline
\end{tabular}

${ }^{*} p<0.05 ;{ }^{* *} p<0.01$.

†Adjusted by age, gender. 
to weight loss, reduces systemic inflammation and has a beneficial association with subclinical atherosclerosis, including coronary artery calcification and intima-media thickness. ${ }^{31}$

This study confirmed that high job strain is significantly related to poor cardiovascular health status, which in this study's groups is mainly due to low physical activity. And this study may also be the first report that nursing professionals and physician assistants have the worst cardiovascular status among medical staff. Furthermore, we comprehensively adjusted the demographic factors and found that physical inactivity was the most prevalent factor impacting the participants' cardiovascular health. Importantly, we recruited most of the medical employees (89\%) and had moderate case numbers in this study, both of which may have increased the reliability of our results.

Although we added new information in this research, several limitations should be addressed. First, we amalgamated seven healthy indicators together to represent cardiovascular health status, but the risk of GVD was different for each factor. It makes sense, if an individual has two unhealthy factors-physical inactivity and obesity-for that individual to possess a different risk of CVD in the future than one who has the paired risks of hypertension and diabetes mellitus. But, as in Rose's theory for a population-level intervention strategy, using aggregated data seemed to be a more simple and feasible method than using individual profiles. ${ }^{32}$ Second, grouping poor cardiovascular health based simply on the presence of at least one poor cardiovascular indicator seems to lead to a major loss of information, which should be further validated. Third, the participants in this study were sampled from medical employees; therefore the results should not be extended to other occupational workers. Fourth, this study was based on questionnaires; selective bias should be taken into consideration. Take, for example, an employee with high strain work characteristics who may have avoided or not had the time to participate in this study. This may have resulted in an underestimation of the prevalence of employees with high work load and burnout. However, the high response rate will limit the magnitude of this discrepancy. Finally, this study can only ascertain the association between job strain and cardiovascular health status, but not the causal relationship, due to the inherent shortcoming of a cross-sectional study. Therefore, further longitudinal study is needed to confirm these relationships.

\section{CONCLUSIONS}

This study demonstrates that lack of physical activity is more common among medical employees who work with high strain. This risk factor creates a possibility of raising the incidence of CVD. Thus, in strategies for work-place health promotion, employers should improve unfavourable work characteristics by carrying out improvements such as reducing work load, stipulating realistic working hours and focusing on high risk groups, in order to increase employees' health literacy and motivation to exercise regularly.

Acknowledgements The authors would like to thank the participants of SLH-HS for their dedication to this study. Miss Lo MY had full access to all of the data in the study and assisted in making the tables and figures. Mr Rod contributed to revisions of the English in this paper.

Contributors All the authors participated in the interpretation of data, and wrote and critically reviewed the paper. L-PC and C-CT designed and conducted the study, and wrote the craft; C-YL was our statistical consultant, who revised and interpreted the tables; SCH directed the entire study and completed the manuscript.

Competing interests None declared.

Ethics approval Ethics Committee of the Sin-Lau Hospital (SLH-919-104-08).

Provenance and peer review Not commissioned; externally peer reviewed.

Data sharing statement No additional data are available.

Open Access This is an Open Access article distributed in accordance with the Creative Commons Attribution Non Commercial (CC BY-NC 4.0) license, which permits others to distribute, remix, adapt, build upon this work noncommercially, and license their derivative works on different terms, provided the original work is properly cited and the use is non-commercial. See: http:// creativecommons.org/licenses/by-nc/4.0/

\section{REFERENCES}

1. Yusuf S, Hawken S, Ôunpuu S, et al., INTERHEART Study Investigators. Effect of potentially modifiable risk factors associated with myocardial infarction in 52 countries (the INTERHEART study): case-control study. Lancet 2004;364:937-52.

2. Akesson A, Larsson SC, Discacciati A, et al. Low-risk diet and lifestyle habits in the primary prevention of myocardial infarction in men: a population-based prospective cohort study. J Am Coll Cardiol 2014;64:1299-306.

3. Kivimäki M, Nyberg ST, Fransson El, et al., IPD-Work Consortium. Associations of job strain and lifestyle risk factors with risk of coronary artery disease: a meta-analysis of individual participant data. CMAJ 2013;185:763-9.

4. Lloyd-Jones DM, Hong Y, Labarthe D, et al. Defining and setting national goals for cardiovascular health promotion and disease reduction: the American Heart Association's strategic Impact Goal through 2020 and beyond. Circulation 2010;121:586-613.

5. Ford ES, Greenlund KJ, Hong Y. Ideal cardiovascular health and mortality from all causes and diseases of the circulatory system among adults in the United States. Circulation 2012;125:987-95.

6. Pieper C, LaCroix AZ, Karasek RA. The relation of psychosocial dimensions of work with coronary heart disease risk factors: a meta-analysis of five United States data bases. Am J Epidemiol 1989;129:483-94.

7. Adler N, Matthews K. Health psychology: why do some people get sick and some stay well? Annu Rev Psychol 1994:45:229-59.

8. Hemingway $\mathrm{H}$, Marmot $\mathrm{M}$. Evidence based cardiology: psychosocial factors in the aetiology and prognosis of coronary heart disease. Systematic review of prospective cohort studies. BMJ 1999;318:1460-7.

9. Kang MG, Koh SB, Cha BS, et al. Job stress and cardiovascular risk factors in Male workers. Prev Med 2005;40:583-8.

10. Nyberg ST, Fransson El, Heikkilä K, et al., IPD-Work Consortium. Job strain and cardiovascular disease risk factors: meta-analysis of individual-participant data from 47,000 men and women. PLOS ONE 2013;8:e67323.

11. Kivimäki M, Singh-Manoux A, Nyberg S, et al. Job strain and risk of obesity: systematic review and meta-analysis of cohort studies. Int $J$ Obes (Lond) 2015;39:1597-600.

12. OECD. Average annual hours actually worked per worker. Organization for Economics Cooperation and Development, 2014.

13. Ho HC, Chang SH, Tsao JY, et al. The relationship between job stress and physical-mental health among hospital staff. Chin J Occup Med 2010;17:239-52.

14. Heinen MM, van Achterberg T, Schwendimann R, et al. Nurses'intention to leave their profession: a cross sectional 
observational study in 10 European countries. Int J Nurs Stud 2013:50:174-84.

15. Chou LP, Li CY, Hu SC. Job stress and burnout in hospital employees: comparisons of different medical professions in a regional hospital in Taiwan. BMJ Open 2014;4:e004185.

16. Karasek R, Baker D, Marxer $F$, et al. Job decision latitude, job demands, and cardiovascular disease: a prospective study of Swedish men. Am J Public Health 1981;71:694-705.

17. Backé EM, Seidler A, Latza U, et al. The role of psychosocial stress at work for the development of cardiovascular diseases: a systematic review. Int Arch Occup Environ Health 2012;85:67-79.

18. Kivimäki M, Nyberg ST, Batty GD, et al. Job strain as a risk factor for coronary heart disease: a collaborative meta-analysis of individual participant data. Lancet 2012;380:1491-7.

19. Pickering TG, Hall JE, Appel LJ, et al., Council on High Blood Pressure Research Professional and Public Education Subcommittee, American Heart Association. Recommendations for blood pressure measurement in humans: an AHA scientific statement from the Council on High Blood Pressure Research Professional and Public Education Subcommittee. J Clin Hypertens (Greenwich) 2005;7:102-9.

20. Yeh W-Y, Cheng Y, Chen C-J, et al. Psychometric properties of the Chinese version of Copenhagen burnout inventory among employees in two companies in Taiwan. Int $J$ Behav Med 2007; 14:126-33.

21. Yeh W, Cheng Y, Chen M, et al. Development and validation of an occupational burnout inventory. Taiwan J Public Health 2008;27:349-64.

22. Karasek RA Jr. Job demands, job decision latitude, and mental strain: Implications for job redesign. Adm Sci Q 1979;24:285-308.
23. Pan WH, Yeh WT. How to define obesity? Evidence-based multiple action points for public awareness, screening, and treatment: an extension of Asian-Pacific recommendations. Asia Pac J Clin Nutr 2008:17:370-4.

24. Folsom AR, Yatsuya $\mathrm{H}$, Nettleton JA, et al. Community prevalence of ideal cardiovascular health, by the American Heart Association definition, and relationship with cardiovascular disease incidence. J Am Coll Cardiol 2011;57:1690-6.

25. Fransson El, Heikkilä K, Nyberg ST, et al. Job strain as a risk factor for leisure-time physical inactivity: an individual-participant meta-analysis of up to 170,000 men and women: the IPD-Work Consortium. Am J Epidemiol 2012;176:1078-89.

26. Centers for Disease Control and Prevention (CDC). Trends in leisure-time physical inactivity by age, sex, and race/ethnicityUnited States, 1994-2004. MMWR Morb Mortal Wkly Rep 2005;54:991-4.

27. World Health Organization. Mortality and burden of disease estimates for WHO Member States in 2004. Geneva: World Health Organization, 2009.

28. O'Keefe JH, Lavie CJ. Run for your life... at a comfortable speed and not too far. Heart 2013;99:516-9.

29. Booth FW, Lees SJ. Fundamental questions about genes, inactivity, and chronic diseases. Physiol Genomics 2007;28:146-57.

30. Lee DC, Pate RR, Lavie CJ, et al. Leisure-time running reduces all-cause and cardiovascular mortality risk. J Am Coll Cardiol 2014;64:472-81.

31. Wong ND, Amsterdam EA, Blumenthal RS. ASPC Manual of Preventive Cardiology: Physical Activity. Ahmed HM, Ndumele CE., Demos Medical Publishing LLC. 2015:163-5.

32. Rose G. Sick individuals and sick populations. Int J Epidemiol 2001;30:427-32. 